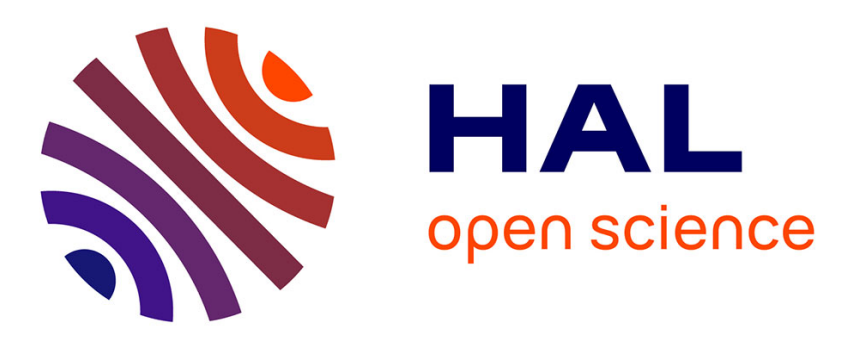

\title{
Cardiovascular complications of lipodystrophic syndromes - focus on laminopathies
}

\author{
Helena Mosbah, Camille Vatier, Franck Boccara, Isabelle Jéru, \\ Marie-Christine Vantyghem, Bruno Donadille, Karim Wahbi, Corinne \\ Vigouroux
}

\section{To cite this version:}

Helena Mosbah, Camille Vatier, Franck Boccara, Isabelle Jéru, Marie-Christine Vantyghem, et al.. Cardiovascular complications of lipodystrophic syndromes - focus on laminopathies. Annales d'Endocrinologie, 2021, 82 (3-4), pp.146-148. 10.1016/j.ando.2020.03.002 . hal-03561213

\section{HAL Id: hal-03561213 https://hal.sorbonne-universite.fr/hal-03561213}

Submitted on 8 Feb 2022

HAL is a multi-disciplinary open access archive for the deposit and dissemination of scientific research documents, whether they are published or not. The documents may come from teaching and research institutions in France or abroad, or from public or private research centers.
L'archive ouverte pluridisciplinaire HAL, est destinée au dépôt et à la diffusion de documents scientifiques de niveau recherche, publiés ou non, émanant des établissements d'enseignement et de recherche français ou étrangers, des laboratoires publics ou privés. 


\section{Cardiovascular complications of lipodystrophic syndromes - focus on laminopathies}

Complications cardiovasculaires des syndromes lipodystrophiques - focus sur les laminopathies

Helena Mosbah ${ }^{\mathrm{a}, \mathrm{b}}$, Camille Vatier ${ }^{\mathrm{a}, \mathrm{b}}$, Franck Boccara ${ }^{\mathrm{b}, \mathrm{c}}$, Isabelle Jéru ${ }^{\mathrm{b}, \mathrm{d}}$, Marie-Christine Vantyghem $^{\mathrm{e}}$, Bruno Donadille ${ }^{\mathrm{a}, \mathrm{b}}$, Karim Wahbi $^{\mathrm{f}}$, Corinne Vigouroux ${ }^{\mathrm{a}, \mathrm{b}, \mathrm{d}}$

aAssistance Publique-Hôpitaux de Paris, Hôpital Saint-Antoine, Centre National de Référence des Pathologies Rares de l'Insulino-Sécrétion et de l'Insulino-Sensibilité (PRISIS) Service d'Endocrinologie, Diabétologie et Endocrinologie de la Reproduction, Paris, France

bSorbonne Université, Inserm UMR_S 938, Centre de Recherche Saint-Antoine, Institut Hospitalo-Universitaire de Cardio-métabolisme et Nutrition (ICAN), Paris, France ${ }^{\mathrm{c} A s s i s t a n c e ~ P u b l i q u e-H o ̂ p i t a u x ~ d e ~ P a r i s, ~ H o ̂ p i t a l ~ S a i n t-A n t o i n e, ~ S e r v i c e ~ d e ~ C a r d i o l o g i e, ~}$ Paris, France

dAssistance Publique-Hôpitaux de Paris, Hôpital Saint-Antoine, Laboratoire Commun de Biologie et Génétique Moléculaires, Paris, France

'Univ. Lille, CHU Lille, Service d'Endocrinologie, Diabétologie et Métabolisme, Inserm U1190 - EGID (European Genomic Institute for Diabetes), Lille, France

fSorbonne Université, Inserm UMR_S970, Assistance Publique-Hôpitaux de Paris, Hôpital Cochin, Service de Cardiologie, FILNEMUS, Paris-Descartes, PARCC (Paris Cardiovascular Research Centre), Paris, France.

Corresponding author: Pr Corinne Vigouroux, Faculté de Médecine Sorbonne Université, 27 rue Chaligny, 75571 Paris. Email : corinne.vigouroux@inserm.fr 


\section{Introduction : lipodystrophy and cardiovascular diseases}

Lipodystrophic syndromes are genetic or acquired rare diseases characterized by a partial or generalized lack of adipose tissue leading to insulin resistance, hypertriglyceridemia and hepatic steatosis. These heterogeneous diseases are of familial or sporadic occurrence, of congenital or delayed clinical expression during childhood or adulthood, and are associated or not with different multi-organ comorbidities, including cardiovascular manifestations [1].

Lipodystrophy-associated cardiovascular involvement is expressed as heterogeneous disorders, either heart muscle diseases, with hypertrophic or dilated cardiomyopathies, rhythm and conduction system diseases, and/or coronary artery disease [2]. Cardiovascular alterations, which are important causes of morbi-mortality in patients with lipodystrophy, result from several non-mutually exclusive mechanisms. Besides the deleterious role of insulin resistance, diabetes, and dyslipidemia, some studies point to additional pathophysiological factors such as cardiac fatty infiltration, fibrosis, autonomic neuropathy, precocious cellular senescence, and cell-autonomous consequences to each specific pathogenic molecular variant [3-7].

The example of laminopathies, due to pathogenic variants in $L M N A$ encoding A-type lamins, illustrates well the challenges of multiple cardiovascular phenotypes associated with lipodystrophy and their consequences for clinical practice.

\section{Laminopathies : a broad spectrum of diseases with different cardiovascular phenotypes}

Although $L M N A$ is ubiquitously expressed in all differentiated tissues, laminopathies form tissue-specific diseases that may clinically translate into skeletal and/or cardiac muscular dystrophies (Emery-Dreifuss muscular dystrophy (EDMD), limb girdle muscular dystrophy 1B (LGMD1B), congenital muscular dystrophy (L-CMD)), dilated cardiomyopathy with conduction defects (DCM-CD), axonal neuropathies (Charcot-Marie-Tooth disease type 2), lipodystrophies or premature ageing syndromes (mandibuloacral dysplasia, Hutchinson-

Gilford progeria syndrome (HGPS), atypical progeroid syndromes, and restrictive dermopathy) [8]. Dunnigan syndrome, also known as familial partial lipodystrophy type 2 (FPLD2), is due to heterozygous LMNA pathogenic variants, with a mutational hot spot 
located at residue Arg482 in the C-terminal part of the protein. It is the most frequent form of genetically-determined lipodystrophy, characterized by partial lipoatrophy with insulin resistance, hypertriglyceridemia, hepatic steatosis, and frequent ovarian hyperandrogenism $[9$, $10]$.

The heart and the vascular wall appear as recurrent targets in most forms of laminopathies. On the one hand, laminopathies of the striated muscle, including EDMD, LGMD1B, L-CMD and DCM-CD, are frequently associated with dilated cardiomyopathy [11]. On the other hand, in LMNA-linked lipodystrophies, frequent and early atherosclerotic cardiovascular events have been reported [3,12]. In addition, HGPS and LMNA-associated premature ageing syndromes are associated with lipoatrophy and with very precocious and severe atherosclerosis and valvular calcifications [13].

\section{Complexity of cardiovascular involvement in the different types of lipodystrophic laminopathies}

In addition to premature atherosclerosis, cardiomyopathic features have been reported in few patients with typical FPLD2 carrying heterozygous substitutions at the codon 482 of the LMNA gene [7]. Furthermore, lipodystrophic complex laminopathy phenotypes, mostly due to non-codon 482-associated LMNA pathogenic variants have been described, associating lipodystrophy and skeletal and/or cardiac dystrophic features [14-19]. Frequent dilated or to a lower extent hypertrophic cardiomyopathies are observed in such patients [7].

Lipodystrophy can also reveal LMNA-associated atypical premature ageing syndromes [20,21]. In affected patients, the cardiovascular phenotype mainly results from valvulopathy and/or atherosclerotic features. However, cardiomyopathy has also been described, and could be worsened by insulin resistance and/or diabetes [22, and personal results].

In $L M N A$-linked lipodystrophies, premature and severe atherosclerosis is not systematically associated with major cardiometabolic risk factors [3,12,23]. Recent studies showing mesodermal and endothelial differentiation defects upon expression of the LMNA p.Arg482Trp variant suggest that developmental alterations could contribute to both lipodystrophy and premature atherosclerosis in FPLD2 [24]. Other pathophysiological 
mechanisms could include defects in prelamin A post-translational maturation leading to both myocardial inflammation and premature senescence of endothelial and smooth vascular muscle cells $[12,25,26]$ and/or laminopathic alterations in extracellular matrix leading to fibrosis [27].

\section{Consequences for clinical practice}

In patients diagnosed with a lipodystrophic syndrome, whatever its etiology, cardiovascular investigations, including at least ECG and echocardiography should be systematically performed [1].

A clear-cut classification of cardiovascular phenotypes among the different tissue-specific laminopathies, involving either heart muscle or the cardiac vasculature, may be challenging. Indeed, in LMNA-linked lipodystrophies, both cardiac muscle and arteries can be affected. Therefore, in each patient diagnosed with lipodystrophy due to a LMNA pathogenic variant, in addition to systematic ECG and echocardiography and even in the absence of any specific sign, other cardiovascular investigations should be systematically discussed, based on genotype, cardiovascular family history, age at diagnosis, and other cardiovascular risk factors. These include a 24-hour Holter ECG monitoring to detect rhythm and/or conduction disturbances, and stress test and/or coronary CT angiogram to detect coronary artery disease. Cardiac MRI should also be discussed evaluating cardiac steatosis and fibrosis.

Cardiovascular specific therapies should be discussed with cardiologists trained in the management of $L M N A$-associated diseases. It should be emphasized that $L M N A$-associated cardiomyopathy may require the implantation of cardioverter-defibrillator to prevent sudden death [28].

Therapeutic management of lipodystrophy-associated metabolic alterations should follow the current international recommendations, with lifestyle and dietary measures being essential for prevention and treatment of metabolic complications [1]. Exercise should be strongly encouraged in the absence of cardiovascular contraindications. Dyslipidemia should be managed in accordance with guidelines for the general population. However, even in patients without diabetes, strict lipid targets (LDL-cholesterol $<100 \mathrm{mg} / \mathrm{dL}$, non-HDL-cholesterol 
$<130 \mathrm{mg} / \mathrm{dL}$, triglycerides $<200 \mathrm{mg} / \mathrm{dL}$ ) are recommended in the context of lipodystrophyassociated increased cardiovascular risk [1]. The association of statins and fibrates should be used with caution in the case of associated muscular dystrophy or inflammatory muscular involvement. The cardiovascular effects of metformin, used as a first-line drug therapy in most patients with lipodystrophy-associated diabetes, and of other non-specific antidiabetic drugs, have not been specifically evaluated in patients with lipodystrophy. The orphan drug metreleptin, a leptin analog, has recently obtained an European Marketing Authorization and is available in France for the treatment of metabolic complications associated with leptin deficiency in selected lipodystrophic patients. In addition to its beneficial effects on insulin sensitivity, insulin secretion and hypertriglyceridemia, metreleptin could decrease LDLcholesterol and PCSK9 serum levels, and improve the atherogenic lipid profile in patients with lipodystrophy [29-31].

\section{Conclusion - Cardiovascular evaluation and management : a systematic requirement for patients with lipodystrophic syndromes}

The clinical and molecular heterogeneity of lipodystrophic syndromes requires a multidisciplinary expertise for each affected patients. At the cardiovascular level, it translates into several manifestations, including cardiomyopathies, rhythm and conduction disturbances and/or coronary artery disease. It is particularly the case for laminopathies, for which cardiovascular evaluation and management requires a close collaboration between endocrinologists and cardiologists.

\section{Funding and Acknowledgments}

The French Reference Center of Rare Diseases of Insulin Secretion and Insulin Sensitivity (PRISIS) is supported by the French Ministry of Solidarity and Health and Assistance Publique-Hôpitaux de Paris, and our research group at Saint-Antoine Research Center (Paris, France) by the Institut National de la Santé et de la Recherche Médicale, Sorbonne Université, and the Fondation pour la Recherche Médicale. We thank Dr Sonja Janmaat for her work as the project manager of the Reference Center PRISIS.

\section{References :}


[1] Brown RJ, Araujo-Vilar D, Cheung PT, Dunger D, Garg A, Jack M et al. The Diagnosis and Management of Lipodystrophy Syndromes: A Multi-Society Practice Guideline. J. Clin. Endocrinol. Metab. 2016;101:4500-4511.

[2] Akinci B, Oral EA, Neidert A, et al. Comorbidities and Survival in Patients With Lipodystrophy: An International Chart Review Study. J Clin Endocrinol Metab. 2019;104:5120-5135.

[3] Hegele RA. Premature atherosclerosis associated with monogenic insulin resistance. Circulation $2001 ; 103: 2225-2229$.

[4] Paauw ND, Stegeman R, de Vroede MAMJ, Termote JUM, Freund MW, Breur JMPJ. Neonatal cardiac hypertrophy: the role of hyperinsulinism-a review of literature. Eur $\mathbf{J}$ Pediatr. 2020;179:39-50.

[5] Ponte CMM, Fernandes VO, Liberato CBR, et al. Association between cardiovascular autonomic neuropathy and left ventricular hypertrophy in young patients with congenital generalized lipodystrophy. Diabetol Metab Syndr. 2019;11:53.

[6] Liu L. Lessons from cavin-1 deficiency. Biochem Soc Trans. 2020; in press.

Liu L. Lessons from cavin-1 deficiency. Biochem Soc Trans. 2020;48(1):147-154.

doi:10.1042/BST20190380

[7] Kwapich M, Lacroix D, Espiard S, Ninni S, Brigadeau F, Kouakam C, et al. Cardiometabolic assessment of lamin $\mathrm{A} / \mathrm{C}$ gene mutation carriers: a phenotype-genotype correlation. Diabetes Metab. 2019;45(4):382-389.

[8] Worman H.J. Nuclear lamins and laminopathies. J. Pathol 2012;226:316-325.

[9] Decaudain A, Vantyghem MC, Guerci B, Hécart AC, Auclair M, Reznik Y, et al. New metabolic phenotypes in laminopathies: LMNA mutations in patients with severe metabolic syndrome. J Clin Endocrinol Metab 2007;92:4835-44.

[10] Gonzaga-Jauregui C, Ge W, Staples J, et al. Clinical and Molecular Prevalence of Lipodystrophy in an Unascertained Large Clinical Care Cohort. Diabetes. 2020;69:249-258.

[11] Lu JT; Muchir A, Nagy PL, Worman HJ. LMNA cardiomyopathy: cell biology and genetics meet clinical medicine. Dis. Model. Mech. 2011;4:562-568.

[12] Bidault G, Garcia M, Vantyghem MC, Ducluzeau PH, Morichon R, Thiyagaraja K, et al. Lipodystrophy-linked LMNA p.R482W mutation induces clinical early atherosclerosis and in vitro endothelial dysfunction. Arterioscler. Thromb. Vasc. Biol. 2013;33:2162-2171.

[13] Hennekam RCM. Hutchinson-Gilford progeria syndrome: review of the phenotype. Am. J. Med. Genet. A. 2006;140:2603-2624.

[14] Van der Kooi AJ, Bonne G, Eymard B, Duboc D, Talim, B, Van der Valk M, et al. Lamin A/C mutations with lipodystrophy, cardiac abnormalities, and muscular dystrophy. Neurology 2002;59:620-623.

[15] Garg A.; Speckman RA, Bowcock AM. Multisystem dystrophy syndrome due to novel missense mutations in the amino-terminal head and alpha-helical rod domains of the lamin A/C gene. Am. J. Med. 2002;112:549-555.

[16] Subramanyam, L, Simha, V, Garg, A. Overlapping syndrome with familial partial lipodystrophy, Dunnigan variety and cardiomyopathy due to amino-terminal heterozygous missense lamin A/C mutations. Clin. Genet. 2010;78:66-73. 
[17] Andre P, Schneebeli S, Vigouroux C, Lascols O, Schaaf M, Chevalier P. Metabolic and cardiac phenotype characterization in 37 atypical Dunnigan patients with nonfarnesylated mutated prelamin A. Am. Heart J. $2015 ; 169: 587-593$.

[18] Francisco ARG, Santos Gonçalves I, Veiga F, Mendes Pedro M, Pinto FJ, Brito D. Complex phenotype linked to a mutation in exon 11 of the lamin A/C gene: Hypertrophic cardiomyopathy, atrioventricular block, severe dyslipidemia and diabetes. Rev. Port. Cardiol. 2017;36:669.e1-669.e4.

[19] Araújo-Vilar D, Lado-Abeal J, Palos-Paz F, Lattanzi G, Bandín MA, Bellido D et al. A novel phenotypic expression associated with a new mutation in LMNA gene, characterized by partial lipodystrophy, insulin resistance, aortic stenosis and hypertrophic cardiomyopathy. Clin. Endocrinol. (Oxf.) 2008;69:61-68.

[20] Caux F, Dubosclard E, Lascols O, Buendia, B, Chazouillères O, Cohen A, et al. A new clinical condition linked to a novel mutation in lamins $\mathrm{A}$ and $\mathrm{C}$ with generalized lipoatrophy, insulin-resistant diabetes, disseminated leukomelanodermic papules, liver steatosis, and cardiomyopathy. J. Clin. Endocrinol. Metab. 2003;88:1006-1013.

[21] Garg A, Subramanyam L, Agarwal, AK, Simha V, Levine B, D’Apice MR et al. Atypical progeroid syndrome due to heterozygous missense LMNA mutations. J. Clin. Endocrinol. Metab. 2009;94:4971-4983.

[22] Hussain I, Patni N, Ueda M, Sorkina E, Valerio CM, Cochran E. et al. A Novel Generalized Lipodystrophy-Associated Progeroid Syndrome Due to Recurrent Heterozygous LMNA p.T10I Mutation. J. Clin. Endocrinol. Metab. 2018;103:1005-1014.

[23] Al-Shali KZ, Hegele RA. Laminopathies and atherosclerosis. Arterioscler Thromb Vasc Biol 2004; 24:1-5

[24] Briand N, Guénantin, AC, Jeziorowska D, ShahA, Mantecon M, Capel E.et al. The lipodystrophic hotspot lamin A p.R482W mutation deregulates the mesodermal inducer T/Brachyury and early vascular differentiation gene networks. Hum. Mol. Genet. 2018;27: 1447-1459.

[25] Brayson D, Frustaci A, Verardo R, Chimenti C, Russo MA, Hayward R et al. Prelamin A mediates myocardial inflammation in dilated and HIV-associated cardiomyopathies. JCI Insight 2019:4.

Brayson D, Frustaci A, Verardo R, et al. Prelamin A mediates myocardial inflammation in dilated and HIV-associated cardiomyopathies. JCI Insight. 2019;4(22):e126315. Published 2019 Nov 14. doi:10.1172/jci.insight.126315

[26] Afonso P, Auclair M, Boccara F, Vantyghem MC, Katlama C, Capeau J, et al. LMNA mutations resulting in lipodystrophy and HIV protease inhibitors trigger vascular smooth muscle cell senescence and calcification: Role of ZMPSTE24 downregulation. Atherosclerosis 2016;245:200-211.

[27] Chatzifrangkeskou M, Le Dour C, Wu W, Morrow JP, Joseph LC, Beuvin, M et al. ERK1/2 directly acts on CTGF/CCN2 expression to mediate myocardial fibrosis in cardiomyopathy caused by mutations in the lamin A/C gene. Hum. Mol. Genet. 2016;25:2220-2233. 
[28] Wahbi K, Ben Yaou R, Gandjbakhch E, Anselme F Gossios T Lakdawala N.K, et al. Development and Validation of a New Risk Prediction Score for Life-Threatening Ventricular Tachyarrhythmias in Laminopathies. Circulation 2019;140:293-302.

[29] Levenson AE, Haas ME, Miao J, et al. Effect of Leptin Replacement on PCSK9 in ob/ob Mice and Female Lipodystrophic Patients. Endocrinology. 2016;157:1421-1429.

[30] Vatier C, Arnaud L, Prieur X, et al. One-year metreleptin therapy decreases PCSK9 serum levels in diabetic patients with monogenic lipodystrophy syndromes. Diabetes Metab. 2017;43:275-279.

[31] Kinzer AB, Shamburek RD, Lightbourne M, Muniyappa R, Brown RJ. Advanced Lipoprotein Analysis Shows Atherogenic Lipid Profile That Improves After Metreleptin in Patients with Lipodystrophy. J Endocr Soc. 2019;3:1503-1517. 